\title{
Alternative sites of ventricular pacing: His bundle pacing
}

\author{
Francesco Vetta ${ }^{1}$, Leonardo Marinaccio ${ }^{2}$, Giampaolo Vetta ${ }^{1}$ \\ ${ }^{1}$ Arrhythmology, Unit Paideia Hospital, Rome; ${ }^{2}$ AULSS6 Euganea, Ospedale Immacolata Concezione, Piove di Sacco, Italy
}

\begin{abstract}
Since its introduction right ventricular apical (RVA) pacing has been the mainstay in cardiac pacing. However, in recent years there has been an upsurge of interest in permanent His bundle pacing (HBP), given the scientific evidence of the harmful role of dyssynchronous ventricular activation, induced by RVA pacing, in promoting the onset of heart failure and atrial fibrillation. After an intermediate period in which attention was focused on algorithms aimed at minimizing ventricular pacing, with partially inadequate and harmful results, scientific attention shifted to HBP, which proved to ensure a physiological electro-mechanical activation of the ventricles. The encouraging results obtained have allowed the introduction of HBP in recent guidelines for cardiac pacing in
\end{abstract}

\section{Correspondence: Francesco Vetta, Arrhythmology Unit, Paideia Hospital, Via Vincenzo Tiberio 46, 00191 Rome, Italy. \\ Tel. +39.06.8276976 - Fax +39.06.8276976. \\ E-mail: vettaaritmologia@gmail.com}

Key words: His bundle pacing; right ventricular pacing; cardiac resynchronization therapy; biventricular pacing; left bundle branch block.

Authors' contributions: All the Authors of this manuscript have equally contributed to the conception, design and editing of the manuscript, as well as to the acquisition, analysis and interpretation of the data entered. All Authors have approved the final version of the submitted manuscript and declare that they are equally responsible for all aspects of the work to ensure that issues relating to the accuracy or integrity of any part of the work are properly investigated and eventually resolved.

Conflict of interest: None of the Authors is involved in any individual situation that may constitute a conflict of interest. No economic funds or reimbursement of expenses have been attributed to the Authors for the elaboration of the present manuscript.

Declaration: The Authors hereby declare that the submitted manuscript is original and has not been submitted previously or simultaneously to other scientific journals.

Received for publication: 18 February 2020.

Accepted for publication: 6 April 2020.

${ }^{\circ}$ Copyright: the Author(s), 2020

Licensee PAGEPress, Italy

Monaldi Archives for Chest Disease 2020; 90:1251

doi: 10.4081/monaldi.2020.1251

This article is distributed under the terms of the Creative Commons Attribution Noncommercial License (by-nc 4.0) which permits any noncommercial use, distribution, and reproduction in any medium, provided the original author(s) and source are credited. patients with bradycardia and cardiac conduction delay. Recent studies have also demonstrated the potential of HBP in patients with left bundle branch block and heart failure. HBP is promising as an attractive way to achieve physiological stimulation in patients with an indication for cardiac resynchronization therapy (CRT). Comparative studies of HB-CRT and biventricular pacing have shown similar results in numerically modest cohorts, although HBCRT has been shown to promote better ventricular electrical resynchronization as demonstrated by a greater QRS narrowing. A widespread use of this pacing technique also depends on improvements in technology, as well as further validation of effectiveness in large randomised clinical trials.

\section{Introduction}

In recent decades right ventricular apical (RVA) pacing has been the cornerstone of cardiac pacing in case of bradycardia. Although for most patients, RVA pacing is safe and highly effective in restoring heart rate and improving bradycardia-induced symptoms, this approach results in a non-physiological electrical and mechanical model of ventricular activation [1]. Several studies have reported the harmful effects of chronic RVA pacing. Clinical observations and large clinical trials have shown that RVA pacing leads to a ventricular dyssynchrony, reduced left ventricular function, and heart failure and increased risk of atrial fibrillation [2-5]. The DAVID (dual-chamber and VVI implantable defibrillator) [6,7] and MOST (Mode Selection Trial) [8] trials have been concordant in highlighting an increased risk of both hospitalization due to heart failure and ventricular tachycardia/ventricular fibrillation episodes [9] in patients receiving a higher burden of RVA pacing. In patients with high-grade atrioventricular block, requiring RVA pacing greater than $40 \%$, a progressive deterioration of ventricular systolic function up to an overt heart failure was noted in $10-26 \%$ of cases [1-5]. Literature data agree that patients with a permanent pacing indication, at greater risk of receiving the deleterious effects of RVA, are those with a left ventricular ejection fraction (LVEF) between $36 \%$ and $50 \%$ and with atrioventricular block that is expected to require ventricular pacing more than $40 \%$ of the time $[10,11]$. In recent years a series of studies have been developed to evaluate the possibility of using alternative pacing sites in the right ventricle. Unfortunately, although recent meta-analyses show some evidence of benefit, most studies have not provided unambiguous and encouraging results, even using different lead positions on the interventricular septum [12]. As a result, a general consensus has developed as to whether the RVA pacing burden should be minimized [13]. Thus, in an attempt to ensure physiological atrioventricular conduction (AV) and to prevent inappropriate ventricular pacing, a series of PMK algorithms have been developed to reduce the RVA pacing burden [14]. Subsequent 
scientific data have regrettably shown that even excessive restriction of RVA pacing can have detrimental clinical effects $[15,16]$. Indeed, maintaining long atrioventricular delays compromises atrioventricular synchronization, increasing the risk of atrioventricular block at higher atrial rates and predisposing to mitral regurgitation. The Minerva Trial, aimed at assessing the incidence of persistent atrial fibrillation, especially in patients with sinus node disease, clearly highlighted the main role of atrioventricular conduction interval analysis, in addition to the RVA pacing rate, in order to ensure the best PMK programming, tailored to the patients' characteristics [17]. Therefore, there is a clear need for new pacing techniques aimed at promoting a more physiological model of ventricular electrical activation, which can ensure the maintenance of contractile function by optimizing atrioventricular synchronization, thus reducing dyssynchrony and clinical complications induced by a high RVA pacing burden. In this context, in recent years, much attention has been paid to His bundle pacing (HBP) as an alternative approach to RVA pacing, with the goal of maintaining a physiological model of ventricular activation through His-Purkinje's native system [18].

Therefore, based on current literature data, the aim of this review is to take stock of the clinical and hemodynamic effects of the use of HBP both in patients with normal left ventricular function and in those with indication for cardiac resynchronization therapy.

\section{His bundle pacing for physiological ventricular activation}

In most people the His bundle lies within the membranous portion of the interventricular septum. The proximal part of His bundle, which is surrounded by fibrous connective tissue rather than myocardium, lies on the right atrial portion of the septum, above tricuspid valve annulus, and then enters, along its course, into the muscular portion of the interventricular septum to finally splits into the right and left bundles [19]. The permanent pacing of His bundle is promising as the most physiological form of cardiac pacing. The first researches have found it feasible, but technically challenging (Figure 1), especially for lead positioning and its stability [20,21]. In recent years, the development of new targeted tools such as SelectSecure 3830 lead (Medtronic, Minneapolis, MN, USA) and delivery sheaths (C315His, C304 SelecSite, Medtronic) have facilitated permanent HBP, making it a safe procedure in routine clinical practice $[22,23]$. Recently, due to both technical progress and increased procedural experience, it has been demonstrated that the feasibility of permanent HBP is $>90 \%[23,24]$. In addition, recent studies suggest that fluoroscopy and procedural timelines are similar to RVA pacing [24]. However, targeted tools are still limited, and sometimes inadequate, mainly for patients with an enlarged right atrium and/or shifted annulus tricuspid [25]. Until recently, there were no established guidelines on the correct terminology to be used regarding the morphology of QRS during HBP. Just over a year ago, a multicentre collaborative working group proposed a nomenclature to help unify terminology with respect to permanent HBP [26]. Two types of His bundle capture have been identified: selective and nonselective (Figures 2 and 3). In selective capture the pacing stimulus captures only His-Purkinje system, producing an interval between the stimulus and the QRS equivalent to the HV interval. In nonselective capture, the stimulus captures both the His bundle and the adjacent ventricular myocardium, generating a fusion wave: pseudodelta wave. Among patients with bundle branch block (BBB) undergoing HBP a narrowing of the QRS may occur for both selective and non-selective capture. Patients with left BBB and nonselective HBP can also demonstrate a third QRS morphology, i.e. that of RV capture alone without apparent His-Purkinje capture. Although selective HBP with BBB correction is desirable, it is not possible in all patients and can only be present on a narrow range of pacing outputs. However, recent literature data seem to suggest favourable and clinically comparable results for both selective and non-selective HBP $[27,28]$. The hemodynamic effects of HBP for physiological ventricular activation can be distinguished into acute and chronic. With regard to the former, the results are varied and partly contrasting, both for the small number and for the clinical variety of patients enrolled in the trials. Some studies have demonstrated a clear acute hemodynamic advantage in HBP compared to RVA pacing, showing an improvement in echocardiographic indices of ventricular synchronization, together with an improvement in LV systolic function and a reduction in the extent of mitral regurgitation [29-32]. In a crossover, double-blind study, the hemodynamic improvements induced by HBP resulted in an improvement in exercise capacity [30]. On the contrary, Padeletti, in an elegant study aimed at evaluating the acute hemodynamic effects of HBP compared to other RV and LV pacing sites, pointed out that only LV pacing allowed to improve the stroke work and stroke volume, suggesting that acute HBP could not improve LV function compared to RV pacing in alternate sites and may be less effective than LV stimulation [33]. With regard to the effects of HBP in the long term, there are several literature data showing an improvement in cardiac function parameters. In a study involving 765 patients (433 with RVA pacing and 332 with HBP) in a 4-year follow-up, the primary endpoint of death, hospitalization for heart failure (HFH), or upgrade to biventricular pacing (BiVP) was significantly reduced in the HBP group compared to RVA pacing ( $25 \%$ vs 32\%; HR: $0.71 ; \mathrm{p}=0.02$ ). This difference was observed mainly in patients with a percentage of ventricular pacing greater than $20 \%$ (25\% in HBP vs $36 \%$ in RVA pacing; HR: 0.65 ; $\mathrm{p}=0.02$ ). The Authors reported a significantly reduced incidence of $\mathrm{HFH}$ in patients with HBP (12.4\% vs 17.6\%; HR: 0.63; 95\%; p=0.02). A trend towards a reduction in mortality just outside the threshold of statistical significance in HBP $(17.2 \%$ vs $21.4 \%, \mathrm{p}=0.06)$ was also

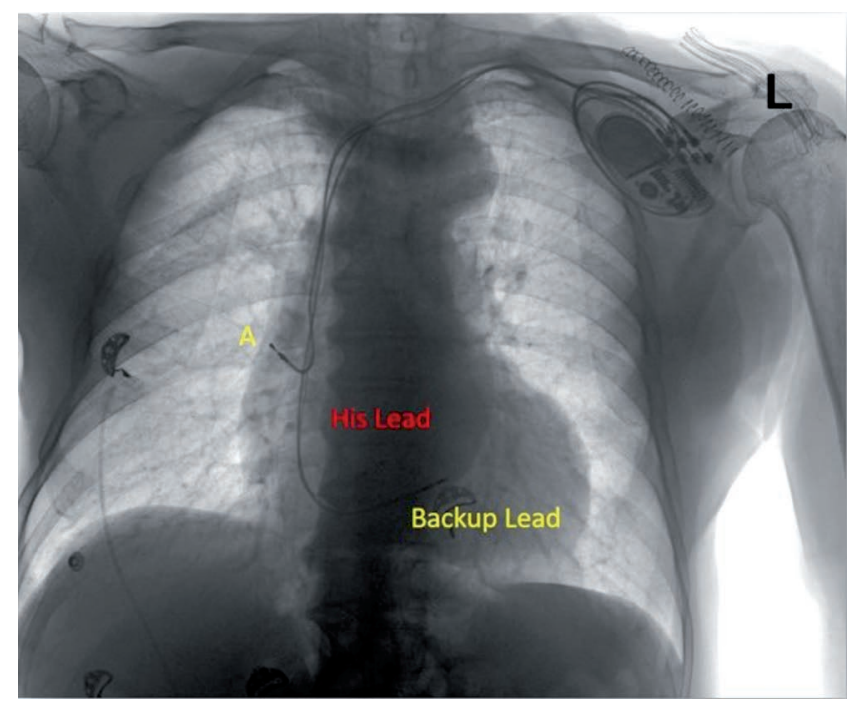

Figure 1. Post implant Rx image. A, Atrial lead positioned in right atrial appendage; His Lead, permanent His bundle pacing in its atrial tract; Backup Lead positioned in RV midseptum. 
observed [34]. In a small trial that enrolled 26 patients, HBP vs RVA pacing was shown to improve LV systolic function and mitral regurgitation at an average follow-up of 36 months [35]. Another randomized crossover trial comparing HBP with RVA pacing in a cohort of patients with preserved systolic function and a QRS duration $<120 \mathrm{~ms}$, showed that HBP, regardless of whether it was selective or non-selective, was associated with an improvement in left ventricular synchronization resulting in an average $5 \%$ increase in the left ventricular ejection fraction at a 1-year follow-up [36]. Taking this scientific evidence into account, recent ACC/American Heart Association guidelines on bradycardia and conduction delay have provided a Class IIa indication for patients with AV block and a LVEF of 36-50\% who have a permanent pacing indication and are expected to require ventricular pacing more than $40 \%$ of the time. A Class IIb indication has been provided for patients with AV block at the AV node level who have an indication for permanent pacing [37].

\section{HBP for cardiac resynchronization}

About 25 years ago, with the introduction of cardiac resynchronization therapy (CRT) we witnessed a paradigm shift for heart failure therapy $[38,39]$. Patients with dyssynchrony caused by advanced heart failure with left bundle branch block (LBBB) $[39,40]$ benefited from synchronous biventricular pacing that improved cardiac output with a narrowing of QRS duration as an expression of improved interventricular as well as intraventricular mechanical synchronicity $[41,42]$. This acquired awareness, combined with evidence of the deleterious effect of RVAP, made biventricular pacing the cornerstone of CRT [39]. Despite the good results of CRT based on biventricular pacing, due consideration should be given to the fact that about $30-40 \%$ of patients do not benefit from this technique $[13,39,43]$. In fact, it is undeniable that biventricular pacing has generated a scientific paradox, since it seeks to promote an improvement in synchronicity by inducing a double electro-induced ventricular dyssynchrony (iatrogenic electropathy), through the fusion of two wavefronts generated, respectively, by the non-physiological endocardial activation of the RV lead and the equally non-physiological epicardial activation of left ventricular lateral wall through a lead positioned there after having travelled backwards through the coronary sinus $[39,44]$. In this cultural context, interest in an HBP-CRT as a potential alternative to biventricular pacing has grown over the last 10 years. Following a series of case reports, Barba-Pichardo and Colleagues [45] published the first trial on the use of HBP in a cohort of 16 patients eligible for CRT with inaccessible coronary sinus to place a lead on LV lateral wall. In contrast to the subsequent trials, no dedicated leads were used in this study, using common leads (Tendril Saint Jude Medical) which required manual adaptation of the stylet curvature to allow placement at His bundle. Although there was a low implantation success rate in this study (56\%) a significant improvement in both LVEF and NYHA class (Table 1) was achieved, with QRS narrowing from an average of $166 \pm 8 \mathrm{~ms}$ to a final value of $97 \pm 9 \mathrm{~ms}(\mathrm{p}<0.01)$. Subsequent trials have all used the fixed helix screw Select-Secure 3830 lead (Medtronic USA) as well as dedicated delivery sheaths (fixed-curve C315 or deflectable C304 SelectSite, Medtronic) that have allowed better success rates for the permanent HBP. These studies all showed an improvement in clinical and echocardiographic parameters in treated patients [4548]. In detail Lustgarten and Colleagues were the first to compare BiV-CRT to HBP-CRT in a crossover study [46]. The Authors used a Y-adaptor connected to both the His and the coronary sinus leads that were both placed into the LV port. Modifying the output of pacing they crossed over patients at 6 months. In both CRT modes there was a significant improvement in quality of life, LVEF and functional parameters such as NYHA class and 6-minute walking test, in the absence of substantial differences between the two different forms of pacing. However, the results of this study were attenuated because of the dropout rate and the impossibility to
A

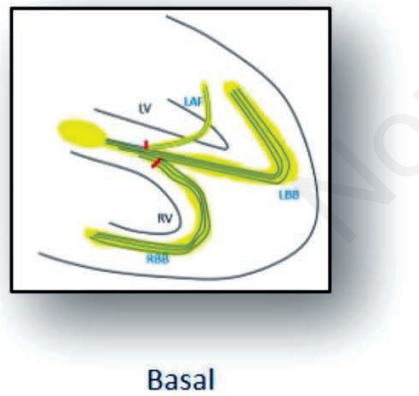

Basal

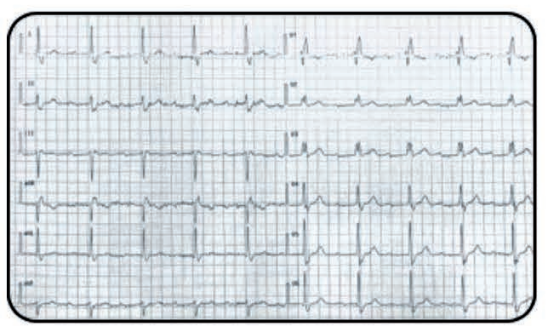

B
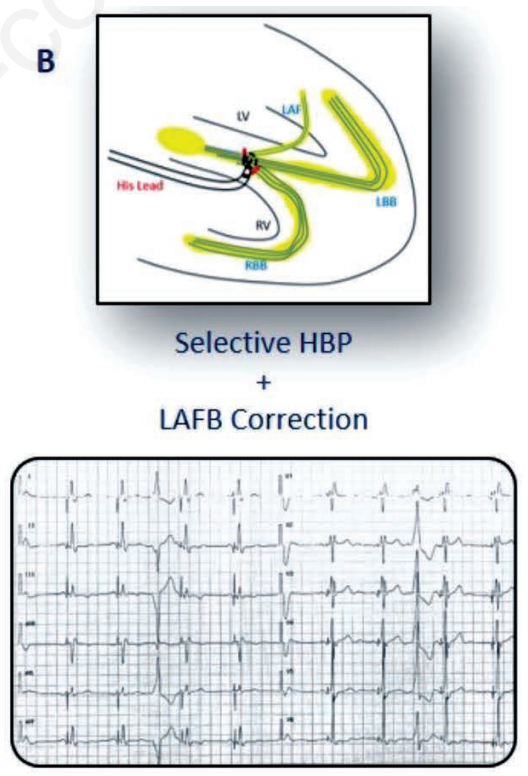

C

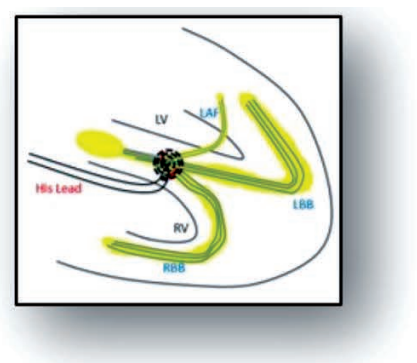

Non Selective HBP

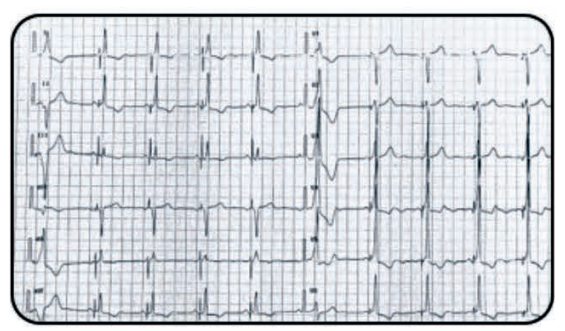

Figure 2. Basal and HB paced EKG, with selective and non-selective capture. A) Basal EKG with RBBB + LAFB. B) Selective HBP with persistent RBBB and LAFB correction. C) Non-selective HBP with correction of both RBBB and LAFB. LV, left ventricle; HBP, His bundle pacing; LAF, left anterior fascicle; LAFB, left anterior fascicle block; LBBB, left bundle branch block; LV, left ventricle; RBBB, right bundle branch block; $R V$, right ventricle. 
exclude that pacing was concomitantly present at both sites considering the use of the Y-adaptor. A recent study aimed at an intra-patient comparison of HB-CRT vs BiV-CRT on acute effects for both ventricular activation times and cardiac hemodynamic functions showed a clear advantage of HB-CRT in favouring ventricular resynchronization as expressed by a more evident reduction in QRS duration $(-18.6 \mathrm{~ms})$, ventricular activation times (more than doubled) and an acute effect on systolic pressure values that was increased by 12.4 vs $7.8 \mathrm{~mm} \mathrm{Hg}$ [49]. Therefore, this study, using a more sophisticated technological approach than Lustgarten's study, already mentioned, confirms the advantages of HB-CRT vs BiV-CRT in terms of acute hemodynamic improvement for interventricular and intraventricular electromechanical resynchronization. In the same direction are the results of the recently published His-SYNC Pilot Trial [50]. While previous work has focused primarily on corrective pacing of His as a rescue strategy for failed biventricular pacing and in limited feasibility studies as a first-line therapy, this pilot trial, although relatively small in number, was the first to formally evaluate HBP as an alternative to traditional biventricular pacing for CRT in patients with heart failure and BBB. In the intention-to-treat analysis QRS duration was reduced more clearly in the HB-CRT group, but the difference between the groups was not statistically significant (HBCRT, from $172 \mathrm{~ms}$ to $144 \mathrm{~ms}$; $\mathrm{p}=0.002$; BiV-CRT from $165 \mathrm{~ms}$ to $152 \mathrm{~ms} ; \mathrm{p}=0.11 ; \mathrm{p}$ for interaction $=0.42$ ). Both groups improved in LVEF between baseline and 6 months (HB-CRT, $26.3 \%$ to $31.9 \%$; BiV-CRT, $30.5 \%$ to $34 \%$; $<<0.001$ for both; $p$ for interaction $=0.33$ ). Furthermore, in the HB-CRT group an increase in LVEF of at least $5 \%$ occurred in $76 \%$ compared to $53 \%$ in the BiV-CRT group $(\mathrm{p}=0.13)$. In the 12-month follow-up there were no differences in the two groups with regard to mortality and hospitalization rates due to cardio-vascular causes. In this study a significantly higher crossover rate from HBP to BiV-CRT $(48 \%)$ was noted compared to the opposite $(26 \%)$, testifying to the existence of numerous grey areas in CRT knowledge. One axiom that emerges clearly from this study is that not all patients can benefit equally from HB-CRT or BiV-CRT: the inclusion in the His-SYNC Trial of patients with nonspecific intraventricular conduction delay (not meeting Strauss criteria) [51] was the major cause of crossover in the HB-CRT group. Finally, although this study was not able to demonstrate a HB-CRT superiority over BiV-CRT in promoting a significant

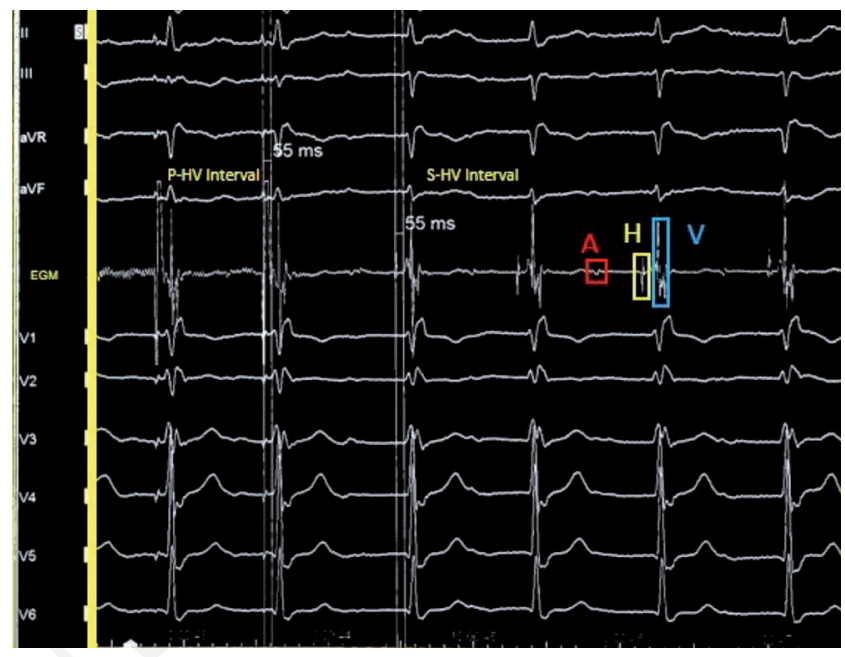

Figure 3. Simultaneous recording of surface and endocavitary electrocardiogram. S-HV interval, Interval between sensed His signal and onset of surface EKG sensed ventricular signal in msec; P-HV interval, interval between paced His signal and onset of surface EKG sensed ventricular signal in msec; $A$, atrial signal; $H$, His signal; V, ventricular signal; EGM, endocavitary electrogram.

Table 1. Main HBP-CRT trials.

\begin{tabular}{|c|c|c|c|c|c|}
\hline Author/year & Patients (n) & Design of the study & HB Lead & Implant success & Main results \\
\hline Barba-Pichardo/2013 [42] & 16 & HBP in BiV-CRT implant failure & $\begin{array}{l}\text { Tendril (SJM) } \\
\text { 1488T, 1788TC, } \\
\text { 1888TC }\end{array}$ & $56 \%$ & $\begin{array}{l}\text { Improvement of NYHA class from III to } \\
\text { II and LVEF from } 29 \% \text { to } 32 \%(\mathrm{p}<0.05)\end{array}$ \\
\hline Lustgarten/2015 [43] & 29 & $\begin{array}{l}\text { Crossover study of HBP and } \\
\text { Biv-CRT }\end{array}$ & $\begin{array}{l}\text { SelectSecure } 3830 \\
\text { (Medtronic) }\end{array}$ & $59 \%$ & $\begin{array}{l}\text { Similar improvement in NYHA class } \\
\text { from } 2 \text { to } 1.9(p<0.001) \text { and in LVEF } \\
\text { from } 26 \% \text { to } 32 \%(p=0.043)\end{array}$ \\
\hline Ajijola/2017 [44] & 21 & Primary HBP-CRT & $\begin{array}{l}\text { SelectSecure } 3830 \\
\text { (Medtronic) }\end{array}$ & $76 \%$ & $\begin{array}{l}\text { Improvement of NYHA class from III to } \\
\text { II }(p<0.001) \text { and LVEF from } 27 \% \text { to } 41 \% \\
(p<0.001)\end{array}$ \\
\hline Sharma/2018 [45] & 106 & HBP in BiV-CRT implant failure & SelectSecure 3830 & $90 \%$ & Improvement of NYHA class from 2.8 \\
\hline & (48 with BBB) & & (Medtronic) & & $\begin{array}{l}1.8(p=0.001) \text { and LVEF from } 30 \% \text { to } \\
43 \%(p=0.0001)\end{array}$ \\
\hline $\begin{array}{l}\text { Upadhyay: His-SYNC } \\
\text { Pilot Trial/2019 [46] }\end{array}$ & 41 & $\begin{array}{l}\text { Multicenter, prospective, } \\
\text { single-blinded, randomized, } \\
\text { controlled trial comparing } \\
\text { HBP-CRT vs BiV-CRT }\end{array}$ & $\begin{array}{l}\text { SelectSecure } 3830 \\
\text { (Medtronic) }\end{array}$ & $92 \%$ & $\begin{array}{l}\text { No significant differences in CV } \\
\text { hospitalization and mortality between } \\
\text { HBP-CRT and BiV-CRT. In the former } \\
\text { group there was a greater QRS } \\
\text { narrowing ( } 174 \text { to } 125 \text { ms us } 165 \text { to } \\
164 \text { ms } \mathrm{p}<0.001 \text { ) and a tendency to } \\
\text { an higher echocardiographic response } \\
(80 \% \text { vs } 57 \% \text { p }=0.14 \text { ) with a better } \\
\text { median change in LVEF ( } 7.2 \text { vs } 5.9 \% \\
p=0.17 \text { ) }\end{array}$ \\
\hline
\end{tabular}


improvement of LV systolic function, this data should not generate the sensation of having obtained a negative, or at least unsatisfactory result, since this study clearly shows the superiority of HB-CRT in promoting electrical resynchronization through a greater shortening of the QRS duration, which is the basis for expecting, in a larger population, more evident cardiac functional changes In any case, the definite evidence that emerges from this trial is that HB pacing has at least equal dignity to BiV pacing within the CRT. In fact, after this trial, if BiV-CRT is unsuccessful, it will be appropriate to try HB pacing for cardiac resynchronization before considering subjecting a patient to the placement of LV epicardial leads, which is significantly more invasive and at greater risk.

\section{Conclusions}

Permanent HBP in recent years is progressively gaining ground given its ability to provide a more physiological model of ventricular pacing that is able to promote atrioventricular, inter and intraventricular synchronicity, mainly because of the negative electro-mechanical consequences of chronic RVA pacing. Although current leads and delivery sheaths allow a high success rate in HBP, the development of new delivery sheaths and leads is necessary in order to reduce both fluoroscopy exposure times and the energy delivered for the pacing threshold, which is higher than traditional RVA pacing. In fact, although almost two decades have passed since the first studies on permanent HB pacing were first introduced, only 1 lead and 2 delivery sheaths are still commercially available, without the existence of His specific pacemakers or pacing algorithms. The good results obtained by HBP, which have included its indication in the guidelines, have progressively expanded its use, also involving patients with heart failure and CRT indication. Literature data suggest a possible non-inferiority of HB-CRT compared to BiV-CRT in improving mortality, hospitalization for HF and LVEF, although the better results obtained in favouring electrical resynchronization through a greater shortening of the QRS duration leave room for a possible improvement of the mechanical cardiac functional parameters, to be evaluated in larger cohorts. However, there are currently a number of obstacles limiting a wide adoption of HB-CRT. In fact, in addition to the already mentioned high capture thresholds with higher energy consumption and the need for additional and more modern leads and delivery sheaths, further trials are needed to better identify patients best served by one or the other CRT mode. While literature data suggest the use of HB-CRT in patients where BiV-CRT is not viable, a possible use of HB-CRT for non-BiV-CRT responders remains to be defined.

\section{References}

1. Rosenqvist $\mathrm{M}$, Isaaz $\mathrm{K}$, Botvinick $\mathrm{EH}$, et al. Relative importance of activation sequence compared to atrioventricular synchrony in left ventricular function. Am $\mathrm{J}$ Cardiol 1991;67:148-56.

2. Tse HF, Lau CP. Long-term effect of right ventricular pacing on myocardial perfusion and function. J AmColl Cardiol 1997; 29:744-9.

3. Thambo J-B, Bordachar P, Garrigue S, et al. Detrimental ventricular remodeling in patients with congenital complete heart block and chronic right ventricular apical pacing. Circulation 2004;110:3766-72.
4. Sweeney MO, Hellkamp AS, Ellenbogen KA, et al. Adverse effect of ventricular pacing on heart failure and atrial fibrillation among patients with normal baseline QRS duration in a clinical trial of pacemaker therapy for sinus node dysfunction. Circulation 2003;107:2932-7.

5. Zhang XH, Chen H, Siu CW, et al. New-onset heart failure after permanent right ventricular apical pacing in patients with acquired high-grade atrioventricular block and normal left ventricular function. J Cardiovasc Electrophysiol 2008;19:136-41.

6. Wilkoff BL, Cook JR, Epstein AE, et al. Dual-chamber pacing or ventricular backup pacing in patients with an implantable defibrillator: The Dual Chamber and VVI Implantable Defibrillator (DAVID) Trial. JAMA 2002; 288:3115-23.

7. Sharma AD, Rizo-Patron C, Hallstrom AP, et al. Percent right ventricular pacing predicts outcomes in the DAVID trial. Heart Rhythm 2005;2:830-4.

8. Link MS, Hellkamp AS, Estes NM, et al. High incidence of pacemaker syndrome in patients with sinus node dysfunction treated with ventricularbased pacing in the Mode Selection Trial (MOST). J Am Coll Cardiol. 2004;43:2066-71.

9. Steinberg JS, Fischer A, Wang P, et al. The clinical implications of cumulative right ventricular pacing in the multicenter automatic defibrillator trial II. J Cardiovasc Electrophysiol 2005;16:359-65.

10. Tops LF, Schalij MJ, Bax JJ. The effects of right ventricular apical pacing on ventricular function and dyssynchrony implications for therapy. JACC 2009;54:764-76.

11. Slotwiner DJ, Raitt MH, Del-Carpio Munoz F, et al. Impact of physiologic versus right ventricular pacing among patients with left ventricular ejection fraction greater than $35 \%$ : a systematic review for the 2018 ACC/AHA/HRS guideline on the evaluation and management of patients with bradycardia and cardiac conduction delay: a report of the American College of Cardiology/American Heart Association Task Force on Clinical Practice Guidleines and the Heart Rhythm Society. Circulation 2019;140:e483-e503.

12. Shimony A, Eisenberg MJ, Filion KB, Amit G. Beneficial effects of right ventricular non-apical vs. apical pacing: A systematic review and meta-analysis of randomized-controlled trials. Europace 2012; 14:81-91.

13. Brignole M, Auricchio A, Baron-Esquivias G, et al. 2013 ESC guidelines on cardiac pacing and cardiac resynchronization therapy: the task force on cardiac pacing and resynchronization therapy of the European Society of Cardiology (ESC). Developed in collaboration with the European Heart Rhythm Association (EHRA). Eur Heart J 2013;34:2281-329.

14. Gillis AM, Puererfellner $\mathrm{H}$, Israel $\mathrm{CW}$, et al. Reducing unnecessary right ventricular pacing with the managed ventricular pacing mode in patients with sinus node disease and AV block. Pacing Clin Electrophysiol. 2006;29:697-705.

15. Stockburger M, Boveda S, Moreno J, et al. Long-term clinical effects of ventricular pacing reduction with a changeover mode to minimize ventricular pacing in a general pacemaker population. Eur Heart J 2015; 36:151-7.

16. Shurrab M, Healey JS, Haj-Yahia S, et al. Reduction in unnecessary ventricular pacing fails to affect hard clinical outcomes in patients with preserved left ventricular function: a meta-analysis. Europace 2017;19:282-8.

17. Boriani G, Pieragnoli P, Botto GL, et al. Effect of PR interval and pacing mode on persistent atrial fibrillation incidence in dual chamber pacemaker patients: a sub-study of the international randomized MINERVA trial. Europace 2019;21:636-44. 
18. Lewis AJM, Foley P, Whinnett Z, et al. His bundle pacing: A new strategy for physiological ventricular activation. J Am Heart Assoc 2019;8:e010972. doi: 10.1161/JAHA.118.010972

19. Vijayaraman P, Dandamudi G. Anatomical approach to permanent His bundle pacing: optimizing His bundle capture. J Electrocardiol 2016;49:649-57.

20. Deshmukh P, Casavant D, Romanyshyn M, Anderson K. Permanent direct His bundle pacing: A novel approach to cardiac pacing in patients with normal His-Purkinje activation. Circulation 2000;101:869-77.

21. Marinaccio L, Giacopelli D, Romanato G, et al. Is dedicated implantation tool set really needed for permanent His bundle pacing? Cardiovas Diagn Ther 2019;9:78-81.

22. Zanon F, Svetlich C, Occhetta E, et al. Safety and performance of a system specifically designed for selective site pacing. Pacing Clin Electrophysiol 2011;34:339-47.

23. Sharma P, Dandamudi G, Naperkowski A, et al. Permanent His bundle pacing is feasible, safe and superior to right ventricular pacing in routine clinical practice. Heart Rhythm 2015;12:305-12.

24. Zanon F, Ellenbogen KA, Dandamudi G, et al. Permanent Hisbundle pacing: a systematic literature review and meta-analysis. Europace 2018;20:1819-26.

25. Ellenbogen KA, Padala SK. His bundle pacing. The holy grail of pacing? J Am Coll Cardiol 2019;71:2331-4.

26. Vijayaraman P, Dandamudi G, Zanon F, et al. Permanent His bundle pacing: recommendations from a multicenter His bundle pacing collaborative working group for standardization of definitions, implant measurements, and follow-up. Heart Rhythm 2018;15:460-8.

27. Upadhyay GA, Tung R. Selective versus nonselective His bundle pacing for cardiac resynchronization therapy. J Electrocardiol 2017;50:191-4.

28. Zhang J, Guo J, Hou X, et al. Comparison of the effects of selective and non-selective His bundle pacing on cardiac electrical and mechanical synchrony. Europace 2018;20:1010-7.

29. Catanzariti D, Maines M, Cemin C, et al. Permanent direct His bundle pacing does not induce ventricular dyssynchrony unlike conventional right ventricular apical pacing. J Interv Card Electrophysiol 2006;16:81-92.

30. Occhetta E, Bortnik M, Marino P. Permanent parahisian pacing. Indian Pacing Electrophysiol J 2007;7:110-2 .

31. Sohaib SA, Wright I, Lim E, et al. Atrioventricular optimized direct His bundle pacing improves acute hemodynamic function in patients with heart failure and PR interval prolongation without left bundle branch block. JACC Clin Electrophysiol 2015;1:582-91.

32. Thosani AJ, Liu E, Shaw G, et al. Rapid reversal of right ventricular pacing-induced cardiomyopathy by His bundle pacing. Heart-Rhythm Case Rep 2017;3:189-91.

33. Padeletti L, Lieberman R, Schreuder J, et al. Acute effects of His bundle pacing versus left ventricular and right ventricular pacing on left ventricular function. Am J Cardiol 2007; 100:1556-60.

34. Abdelrahman M, Subzposh FA, Beer D, et al. Clinical outcomes of His bundle pacing compared to right ventricular pacing. J Am Coll Cardiol 2018;71:2319-30.

35. Catanzariti D, Maines M, Manica A, et al. Permanent Hisbundle pacing maintains long-term ventricular synchrony and left ventricular performance, unlike conventional right ventricular apical pacing. Europace 2012;15:546-53.

36. Kronborg MB, Mortensen PT, Poulsen SH, et al. His or paraHis pacing preserves left ventricular function in atrioventricular block: a double-blind, randomized, crossover study. Europace 2014;16:1189-96.

37. Kusumoto FM, Schoenfeld MH, Barrett C, et al. 2018 ACC/AHA/HRS Guideline on the evaluation and management of patients with bradycardia and cardiac conduction delay. JACC 2019;74:e51-156.

38. Cazeau S, Ritter P, Bakdach S, et al. Four chamber pacing in dilated cardiomyopathy. Pacing Clin Electrophysiol 1994;17:1974-9.

39. Vetta F, Vetta G, Bracchitta S, et al. Cardiac resynchronization therapy in the elderly. How far is it safe and beneficial? Monaldi Arch Chest Dis 2019;89;1025.

40. Grines CL, Bashore TM, Boudoulas H, et al. Functional abnormalities in isolated left bundle branch block. The effect of interventricular asynchrony. Circulation 1989;79:845-53.

41. Foster AH, Gold MR, McLaughlin JS. Acute hemodynamic effects of atrio-biventricular pacing in humans. Ann Thorac Surg 1995;59:294-300.

42. Cazeau S, Ritter P, Lazarus A, et al. Multisite pacing for endstage heart failure: early experience. Pacing Clin Electrophysiol 1996;19:1748-57.

43. Mullens W, Grimm RA, Verga T, et al. Insights from a cardiac resynchronization optimization clinic as part of a heart failure disease management program. J Am Coll Cardiol 2009;53: 765-73.

44. Ploux S, Eschalier R, Whinnett ZI, et al. Electrical dyssynchrony induced by biventricular pacing: implications for patient selection and therapy improvement. Heart Rhythm 2015;12:782-91.

45. Barba-Pichardo R, Manovel Sanchez A, Fernandez- Gomez JM, et al. Ventricular resynchronization therapy by direct His-bundle pacing using an internal cardioverter defibrillator. Europace 2013;15:83-8.

46. Lustgarten DL, Crespo EM, Arkhipova-Jenkins I, et al. Hisbundle pacing versus biventricular pacing in cardiac resynchronization therapy patients: a crossover design comparison. Heart Rhythm 2015;12:1548-57.

47. Ajijola OA, Upadhyay GA, Macias C, et al. Permanent Hisbundle pacing for cardiac resynchronization therapy: initial feasibility study in lieu of left ventricular lead. Heart Rhythm 2017;14:1353-61.

48. Sharma PS, Dandamudi G, Herweg B, et al. Permanent Hisbundle pacing as an alternative to biventricular pacing for cardiac resynchronization therapy: a multicenter experience. Heart Rhythm 2018;15:413-20.

49. Arnold AD, Shun-Shin MJ, Keene D, et al. His resynchronization versus biventricular pacing in patients with heart failure and left bundle branch block. J Am Coll Cardiol 2018;72:3112-22.

50. Upadhyay GA, Vijayaraman P, Nayak HM, et al. On-treatment comparison between corrective His bundle pacing and biventricular pacing for cardiac resynchronization: A secondary analysis of the His-SYNC Pilot Trial. Heart Rhythm 2019;16:1797-807.

51. Strauss DG, Selvester RH, Wagner GS. Defining left bundle branch block in the era of cardiac resynchronization therapy. Am J Cardiol 2011;107:927-34. 